\title{
Paul Otlet: um pioneiro da organização das redes mundiais de tratamento e difusão da informação registrada
}

\author{
Paola Santos \\ Mestre em ciência da informação pela Escola de Comunicações \\ e Artes/USP. \\ E-mail: paolasan@usp.br
}

\section{Resumo}

Estudo da obra de Paul Otlet, com ênfase no Princípio Monográfico, uma de suas principais contribuições para a constituição da documentação e da ciência da informação e predecessora da idéia de hipertexto. Sua obra Traité de Documentation: le livre sur le livre: théorie et pratique, publicada em 1934, antecipa muitas das idéias hoje adotadas sobre a organização de redes internacionais de cooperação para tratamento e troca de informações documentadas. Nessa obra, Otlet define o campo da documentação e sistematiza teorias, métodos e técnicas para organizar o conhecimento registrado e distribuí-lo. Revisitar a obra de Otlet é fundamental para compreender muitos aspectos teóricos, metodológicos e epistemológicos que construíram o campo da documentação e da ciência da informação.

\section{Palavras-chave}

Princípio monográfico. Paul Otlet. Documentação. Ciência da informação.

Paul Otlet: a pioneer of the organization of world nets dealing with dissemination of registered information

\section{Abstract \\ A study of the works by Paul Otlet which emphasize the Monographic Principle: one of his major contributions for the establishment of Documentation and Information Science, and a predecessive idea of hypertext. Otlet's 1934 book Traité de Documentation: le livre sur le livre: théorie et pratique announces many of the current ideas about the organization of cooperative, international networks for processing and exchanging document information. In this work, Otlet defines the field of Documentation and establishes theories, methods and techniques to organize and distribute recorded knowledge. A review of Otlet's work is fundamental for understanding many of the theoretical, methodological and epistemological underpinnings of Documentation and Information Science.}

\section{Keywords}

Monographic principle. Paul Otlet. Documentation. Information Science.

\section{INTRODUÇÃO}

Paul Otlet foi um dos fundadores da documentação. Neste trabalho será discutido o percurso de construção desse campo disciplinar, enfatizando-se o Princípio Monográfico, uma das principais contribuições de Otlet para a consolidação teórica e prática da documentação. Nessa perspectiva, serão examinadas partes do Traité de Documentation, obra na qual Otlet define o campo teórico da documentação, suas leis e métodos, bem como os aspectos essenciais à compreensão do Princípio Monográfico.

A documentação nasceu de um movimento surgido no final do século XIX e início do século XX, na Europa, com o objetivo de encontrar alternativas para organizar a massa crescente de documentos produzidos no período. Esse movimento, que envolveu cientistas, pesquisadores, bibliotecários e bibliógrafos, ficou conhecido como Movimento Bibliográfico.

A intenção de Paul Otlet, ao participar do Movimento Bibliográfico, era dar à documentação um caráter científico. Suas propostas estão expostas no Traité de Documentation: le livre sur le livre: théorie et pratique, publicado em 1934, obra que representa a maturidade do seu pensamento sobre a organização e o acesso ao conhecimento. No Traité, Paul Otlet define o objeto de estudo da documentação - o documento -, propõe metodologias e técnicas para estudá-lo, sinalizando também para a necessidade de criar algumas interdisciplinas, constituídas pelas interfaces com a sociologia, psicologia, lógica, lingüística, estatística, entre outras. Essa visão ampla revolucionou não só o modo de trabalhar com a informação no seu tempo, mas também teve impactos que perduram até hoje.

Na contemporaneidade, os estudos sobre a obra de Otlet têm sido retomados por inúmeros pesquisadores, tais como W. Boyd Rayward, professor da Universidade de Chicago, biógrafo de Otlet, Michael Buckland, professor da Universidade da Califórnia, Bernd Frohmann, professor da Faculdade de Estudos de Informação e Mídia do Canadá, José Lopes Yepes, da Universidade Complutense de Madrid, entre outros. 
No Brasil, destaca-se, dentre outros trabalhos, a tese de livre docência da professora Hagar Espanha Gomes, $\mathrm{O}$ pensamento de Paul Otlet e os princípios do UNISIST, defendida na Universidade Federal Fluminense em 1975. Em 1986, Edson Nery da Fonseca publicou a coletânea Bibliometria: teoria e prática, na qual figura a tradução de uma seção do Traité de Documentation chamado O livro e a medida: bibliometria, na qual Otlet discute a aplicação da matemática e da estatística à bibliologia. Edson Nery da Fonseca também é autor do texto A classificação decimal universal no Brasil, publicado como apêndice da edição brasileira do livro Documentação, de Bradford, no qual estão registradas informações sobre a participação brasileira no Institut International de Bibliographie. Em 2000, as professoras Maria Nazaré Freitas Pereira e Lena Vânia Ribeiro Pinheiro organizaram a coletânea O sonho de Otlet: aventura em tecnologia da informação e comunicação, cujo prefácio, de autoria de Maria de Nazaré Freitas Pereira, relaciona Paul Otlet à internet. Em 2002, Maria de Fátima Tálamo et alii apresentaram o trabalho Otlet, o criador de estruturas informacionais pela paz mundial, no $20^{\circ}$ Congresso Brasileiro de Biblioteconomia, Documentação e Ciência da Informação. O texto trata das tecnologias que Otlet utilizou na construção do Répertoire Bibliographique Universel e dos planos arquitetônicos do Mundaneum. Jaime Robredo publicou em 2003 o livro Da Ciência da Informação revisitada aos sistemas humanos de informação, no qual aborda, entre outros aspectos históricos da ciência da informação, o Movimento da Documentação e a contribuição de Otlet para a documentação.

Ressalta-se ainda a presença dos princípios otletianos na criação de instituições brasileiras como o Instituto Brasileiro de Bibliografia e Documentação (IBBD), hoje Instituto Brasileiro de Informação em Ciência e Tecnologia (Ibict). Mas o capítulo brasileiro dessa história merece estudo aprofundado, retornando-se, no mínimo, ao princípio do século XX. Citam-se, como exemplo, dois dos mais relevantes episódios do envolvimento do Brasil na história da documentação. Em 1911, Manoel Cícero Peregrino da Silva, diretor da Biblioteca Nacional do Rio de Janeiro, utilizou-se do serviço de consulta ao Répertoire Bibliographique Universel (RBU). Essa consulta é reputada por Rayward (1975) como o maior evento na história da distribuição do RBU, quando foram encomendadas 600 mil fichas para formar o repertório de assuntos gerais do recémcriado Serviço de Bibliografia e Documentação da Biblioteca Nacional. Entretanto, o envolvimento do Brasil com o instituto belga é ainda anterior. Registrase na literatura da documentação brasileira a publicação, em 1901, do artigo A bibliographia universal e a classificação decimal, pelo então diretor da Escola Polytechnica de São Paulo, Victor da Silva Freire, no anuário da instituição. Nesse artigo, Freire faz um estudo da Classificação Decimal Universal (CDU), apresentando as divisões gerais da tabela e as subdivisões da área de "engenharia ou arte do engenheiro". No mesmo texto, defende a participação do Brasil na organização da "Bibliografia Universal de Bruxelas". O estudo de Freire foi publicado em opúsculo e numerado pelo Institut International de Bibliographie (IIB). Segundo Fonseca (1961), foi um dos primeiros a ostentar o índice da CDU na própria folha de rosto. Os episódios mencionados anteriormente por si só revelam a força com que o pensamento de Otlet marcou o desenvolvimento da documentação nas instituições brasileiras.

Diversos instrumentos documentários foram concebidos e construídos por Otlet durante seu trabalho no IIB; seu mérito, sem dúvida, foi o de ter reunido teoria e prática em um trabalho incansável para a consolidação de novas metodologias para a análise e síntese do conhecimento, visando à sua circulação. A erudição, o interesse pelas ciências em geral e pelas ciências sociais em particular e seu entusiasmo por certas vertentes do positivismo e cientificismo dominantes na época marcaram sua atuação. $\mathrm{Na}$ raiz do pensamento de Otlet está a crença de que a universalização do acesso ao conhecimento seria o caminho para a paz mundial. Esses aspectos são indissociáveis da proposta de criação do campo da documentologia ou bibliologia.

As formulações de Otlet, tais como o Princípio Monográfico, a Classificação Decimal Universal e a tecnologia das fichas padronizadas, são as bases de um ambicioso projeto de cunho universalista. Constituem técnicas e tecnologias elaboradas por meio da observação empírica e interlocução com pensadores e cientistas unidos em torno da organização do conhecimento. São pontos de partida para idealizações como a construção de um livro universal, apenas superadas pelo desenvolvimento da microinformática, na década de 1980, e, posteriormente, pela internet. Ao lado desses princípios e técnicas, Otlet destaca o papel das instituições, consideradas fundamentais para garantir a cooperação e o intercâmbio entre os sistemas de informação, de modo a formar redes. Esses são os principais traços do modelo desenhado por ele para pensar e trabalhar o conhecimento e a informação, prenunciando as formas de tratamento e circulação da informação que serão adotadas a partir da segunda metade do século XX. 


\section{TRAITÉ DE DOCUMENTATION}

O Traité de Documentation expressa a maturidade do pensamento de Paul Otlet sobre a organização do conhecimento. É, de fato, a primeira sistematização sobre a documentação, que resultou de suas reflexões sobre o trabalho realizado no IIB. Nele, Otlet expõe os princípios fundamentais da documentação e da bibliologia. A bibliologia, contudo, não é uma criação de Otlet. O termo foi cunhado em 1802 por Gabriel Peignot, que a caracterizou como uma ciência que estudava o livro. No Traité de Documentation, Otlet toma a bibliologia como ponto de partida para o desenvolvimento da documentação.

Ao longo dos cinco capítulos do Traité de Documentation, Otlet define os principais conceitos do novo campo como o termo documento -, desenvolve as metodologias do trabalho da documentação, define seu campo de estudos e suas relações com as demais ciências, faz um estudo detalhado do livro, apresenta os produtos do desenvolvimento tecnológico de sua época e suas aplicações à documentação, propondo, por fim, uma rede universal de informação e documentação.

No capítulo quatro, intitulado Organisation rationnelle des livres e des documents, Otlet desenha o seu sistema de informação, ou seja, normatiza a documentação. É neste capítulo, também, que trata dos princípios que constituirão uma enciclopédia documentária ou o livro universal. Segundo suas palavras:

O livro é tradicionalmente formado por folhas encadernadas, porém o conteúdo de um livro pode ser representado numa única linha contínua, seccionada em partes iguais que correspondem às páginas. Esta divisão é material; não concorda com a divisão intelectual das idéias (capítulos, seções, parágrafos, alíneas).

A disposição sob a forma de folhas ou fichas móveis não encadernadas permite obter as vantagens dos três seguintes princípios:

a) Princípio da monografia: cada elemento intelectual de um livro é (depois de ser seccionado do conjunto do texto) incorporado num elemento material correspondente.

b) Princípio da continuidade e da pluralidade da elaboração: quando um livro é elaborado intelectualmente por um ou vários colaboradores, ele termina na sua última página, as fichas permitem o trabalho de um número ilimitado de pessoas e nunca é considerado uma obra acabada. c) Princípio da multiplicação dos dados: para que figurem os diversos dados nas diversas ordens de classificação (por exemplo, as ordens ideológicas, geográficas, cronológicas, etc.) multiplicam-se as fichas dos mesmos(OTLET, 1934, p. 385-386).

No fragmento anterior, está enunciado o Princípio da Monografia ou o Princípio Monográfico. Esse princípio caracteriza-se como o procedimento pelo qual se fazem coincidir o "elemento intelectual" e o suporte físico da informação. Na prática, trata-se de extrair dos textos aquilo que era considerado novo e informativo e compor um novo volume, constituído de fichas ou folhas soltas. Obtinha-se, com isso, uma nova unidade autônoma de informação.

Na concepção otletiana, os livros e os documentos trazem partes de descobertas científicas, sendo que muitos documentos acabam por repetir os conhecimentos sobre determinado fato ou assunto; na visão de Otlet, a reiteração deveria ser suprimida, em favor da objetivação da informação, de modo a promover a economia de tempo do leitor. Seu objetivo principal era, portanto, selecionar os dados que poderiam ser posteriormente tratados por meio dos dois outros princípios: a) o Princípio da continuidade e da pluralidade da elaboração, que consistia na redação de fichas analíticas, com campos de dados padronizados que serviam para acrescentar dados objetivos sobre o texto analisado, tais como autoria, título, etc., que indicassem a origem da informação tratada; b) o Princípio da multiplicação dos dados que consistia na duplicação das fichas de acesso à informação intercalandoas sob as rubricas das várias facetas da CDU. Esse procedimento possibilitava o acesso à informação por vários pontos de acesso do sistema.

O Princípio Monográfico, se aplicado de forma ingênua, poderia provocar a dispersão da informação. Esse problema poderia ser evitado recorrendo-se a uma estrutura lógica de organização da informação representada pela CDU, instrumento que serviria tanto para armazenar, quanto para recuperar informação.

O Livro Universal, obtido pela aplicação dos diferentes princípios propostos pela documentação, promoveria o mapeamento de todo o conhecimento produzido pelo homem. Por meio da objetivação e contextualização da informação, segundo Otlet, seriam criados novos discursos, do ponto de vista do próprio sistema. Em contrapartida, o sistema poderia oferecer várias possibilidades de acesso às informações, já que o discurso, fragmentado e tratado pelas tabelas da CDU, poderia ser recontextualizado pelo pesquisador. Otlet estava, na verdade, tentando escrever um novo tipo de livro, aquele que seria lido por toda a humanidade. Segundo Otlet, 
a informação, da qual foram retirados todos os elementos estranhos e a ganga, será publicada de maneira bastante analítica. Será registrada em folhas separadas ou fichas ao invés de ficarem confinadas em volumes... Pela união destas folhas, e classificando-as e organizando-as de acordo com os cabeçalhos de uma classificação confiável, precisa e detalhada, criaremos o Livro Universal do conhecimento, um livro que jamais estará completo, mas que crescerá incessantemente (OTLET apud FROHMANN, 2000, p. 6).

A Enciclopédia Documentária era composta por Dossiês Enciclopédicos Documentários. Estes eram formados por partes de documentos, reunidos em pastas classificadas por assunto, permitindo ao usuário ter noção sobre a totalidade das informações sobre determinado assunto "sob todos os pontos de vista” (OTLET, 1934, p. 409), ou seja, para que o usuário pudesse formar sua própria opinião sobre o tema pesquisado, não poderia haver qualquer tipo de triagem ideológica do material sistematizado nos dossiês.

A Enciclopédia Documentária era formada também pelos Repertórios Enciclopédicos de Fichas, que se diferenciavam dos Dossiês apenas pelo formato; este repertório era composto de recortes, ou cópias de publicações, e de anotações feitas sobre as fichas e folhas padronizadas. Além dos dois anteriores, constituíam a Enciclopédia Documentária os materiais especialmente produzidos para serem a ela incorporada.

A totalidade do conhecimento, consolidada na Enciclopédia, era composta por fragmentos dos documentos, relacionados por métodos documentários, de modo a formar grandes conjuntos informativos. Evidencia-se, aqui, a concepção de Otlet: o prédio do conhecimento deveria ser construído com os tijolos da informação.

\section{A DEFINIÇÃO DO CAMPO DA DOCUMENTAÇÃO POR OTLET}

No Traité de Documentation, Otlet estabelece o campo de investigação da documentação. Dedica grande parte desse texto ao estudo sistemático do livro em si e dos documentos escritos em geral, bem como das mídias surgidas no início do século XX, tais como o telégrafo, o telefone, o rádio, a televisão, o cinema e os discos, todos eles definidos pelo autor como "substitutos do livro". Será sobre o objeto livro, em sentido amplo, que Otlet estabelecerá as metodologias e procedimentos de uma nova "ciência" - a documentação.

Para estudar o livro, Otlet recupera e revitaliza a bibliologia, "ciência do livro". Segundo Robert Estivals, bibliólogo e professor da Université de Bordeaux III, a bibliologia era uma ciência descritiva e histórica que Otlet retoma, estabelecendo novos parâmetros para inseri-la nas perspectivas científicas do século XX. Desse modo, toma a bibliologia como ponto de partida de suas reflexões, aproveitando seu objeto de estudo e metodologia. Amplia, porém, o objeto de estudo - do livro para o documento -, formula novas metodologias de investigação do objeto e cria nova terminologia para a área.

Embora sejam propostos novos conceitos e termos para a ciência em construção, observa-se que não há, ao menos no Traité de Documentation, a fixação dessa terminologia. Segundo Estivals, no texto de Otlet a "Bibliologia se confunde com a documentologia”, não ficando claramente estabelecidas as fronteiras entre os dois campos (ESTIVALS, 1987, p. 13). Essa visão é confirmada por López Yepes, ao afirmar que "bibliologia, documentação e documentologia são três denominações propostas por Otlet para a ciência geral do documento..." (LOPEZ YEPES, 1978, p. 45).

Acredita-se que a dificuldade de fixação terminológica já se inicie com a problemática definição dos objetos de estudo: o livro, o documento e os substitutos do livro. Para Otlet, os substitutos do livro são todos os meios que servem para informar e comunicar algo e que não tenham a escrita como principal meio de expressão. Dessa forma, entram nessa categoria os objetos de museus, maquetes, o telégrafo, o telefone, o rádio, a televisão, o cinema, os discos entre outros.

Tendo em vista essas dificuldades, será utilizado preferencialmente o termo documentação neste texto. Não se poderá descartar, entretanto, o termo bibliologia, por ser ele justamente o mais utilizado no Traité de Documentation. Entende-se, portanto, que bibliologia e documentação são termos equivalentes.

\section{O objeto da bibliologia/documentação: o livro}

O livro, no conceito clássico da cultura ocidental, é uma completude em si, caracterizado"

por uma noção de fechamento, identidade individual e verdade representacional. Ou seja, os livros são individuais, completos e davam uma imagem verdadeira da realidade." (DAY, 1997, p. 311).

Do ponto de vista da documentação, Otlet vê no livro uma organicidade. O livro é uma estrutura constituída por partes, sendo ele próprio parte constitutiva de uma rede composta por todos os livros. Otlet apóia essa afirmação recorrendo à lei da conservação de energia, da 
físico-química, que preconiza que "nada se perde, nada se cria, tudo está em transformação"; aplicada ao livro, tal lei tomará a seguinte forma:

Os livros conservam energia mental, o conteúdo dos livros passa a outros livros quando eles mesmos são destruídos e toda criação bibliológica, por mais original e poderosa que seja, implica redistribuição, combinação e novas amalgamações dos dados anteriores (OTLET, 1934, p. 422-423).

Essa afirmação torna-se mais clara quando se pensa nos elementos presentes no livro, tais como notas de rodapé, remissões a outras obras e a bibliografia consultada e recomendada.

Para Otlet, o livro é a materialização do pensamento; este, por sua vez, é a imagem das coisas, é a imagem daquilo que existe; o livro é, pois, uma reprodução da realidade que tem o mundo como modelo; em decorrência, o livro seria, por acumulação ou no seu conjunto, a própria realidade registrada.

O livro é, entretanto, mais do que um mecanismo acumulador, pois "ele se desenvolve em detrimento do cérebro como a ferramenta se desenvolve em detrimento dos corpos" (OTLET, 1934, p. 426), é "força intelectual condensada com poder de expansão considerável" (OTLET, 1934, p. 425). Configura-se, nessa medida, de acordo com os padrões científicos positivistas de sua época, como reprodução da realidade, embora com potencial de modificar a consciência e a própria condição humana.

O livro é, na concepção de Otlet, um instrumento de abstração que funciona como uma extensão do cérebro. Nessa medida, é análogo ao microscópio e ao telescópio, porque dá ao homem o poder de ver além, superando as limitações dos órgãos da visão. O livro promove, pois, o desenvolvimento do cérebro por meio da abstração. Sua construção, no entanto, requer a participação do leitor porque este, no ato da leitura, recorre ao seu próprio acervo de conhecimentos e experiências individuais para compreendê-lo, modificá-lo e enriquecê-lo.

O livro é ao mesmo tempo um instrumento e um símbolo do aperfeiçoamento da humanidade. Essa dupla natureza ocorre porque o livro opera como um instrumento não só de registro e perpetuação do pensamento e da realidade, mas também de construção de novos pensamentos e de novas realidades. Dessa forma, atua tanto no pólo da produção, por meio dos escritores, como no do consumo, por meio dos leitores.
Atua também para além deles, para a sociedade, pois não só permite traduzir e transmitir o pensamento, mas também formá-lo. É dessa perspectiva que enxerga seu papel social, sua natureza libertadora de qualquer "tipo de submissão mental ou vida imposta ao homem" (OTLET, 1934, p. 427).

Como instrumento intelectual, o livro pode ser visto pelo artista como o princípio e o fim do universo, pelo cientista, como uma construção intelectual coerente e lógica do universo, e, pelo sociólogo, como a contribuição para o equilíbrio da sociedade. O livro é, em contraposição, um grande gerador de ilusões, que responde a uma necessidade emocional profunda do ser humano por ideais estéticos, religiosos ou mesmo científicos. Essa multiplicidade de forças presentes no livro faz com que ele seja um regulador social e um instrumento para promover a liberdade, a igualdade e a unidade, exercendo papel fundamental no desenvolvimento da humanidade (OTLET, 1934).

Otlet manifesta uma profunda crença no papel social e na função educativa do livro, uma vez que ele representa o mundo, porque contém dados observados da realidade, e enfeixa a síntese do progresso da humanidade. Recorrendo a um sistema de signos desenvolvidos pelo homem, no correr dos séculos, inscrito sobre suportes práticos e portáveis, com o emprego das tecnologias características de cada época, dando lugar a anotações que possam ser conservadas, comunicadas e difundidas, o livro é veículo de comunicação do conhecimento.

Do ponto de vista bibliológico, para Otlet a

aparência exterior do livro, sua forma, a personalidade do autor têm pouca importância, o que importa é sua substância a qual deveria ser conservada e tornada parte de um 'organismo de ciência', algo impessoal criado pelo trabalho de todos (RAYWARD, 1975, p. 31).

Para Otlet, portanto, o que realmente importa é o conhecimento novo, produto de atos coletivos, identificado e colocado em um sistema de informação.

$\mathrm{Na}$ concepção de Otlet, a bibliologia vê todos os livros como um só. Na sua projeção do livro em direção ao futuro, não só propõe como inicia o "livro universal" ou a "enciclopédia documentária”, nas quais se encontrará o conhecimento organizado e acessível a todos. Esta proposta está certamente inserida em uma visão enciclopedista e se alinha à visão de cientistas e pensadores do início do século XX, tais como H.G. Wells, Wilhelm Ostwald e Otto Neurath. 
A maneira de organizar o conhecimento, tendo em vista seu acesso universal, pressupõe o emprego de tecnologia em ampla escala. Não se trata apenas de prefigurar os possíveis contornos que o livro assumirá no futuro, mas de trabalhar concretamente com as técnicas e tecnologias disponíveis para criá-lo. Será possível criar tal livro por meio dos repertórios universais, organizados pelo IIB, a instituição que materializa os ideais, metodologias, técnicas e tecnologias preconizadas por Otlet. Muito provavelmente o desenvolvimento dos repertórios era encarado por ele como uma evolução do livro, em direção ao "livro universal", no qual todo o saber, na sua essência, estivesse objetivado, atualizado e organizado de maneira eficiente e facilmente acessível.

Os elementos básicos utilizados na tecnologia dos repertórios eram as fichas de "informação" - nas quais se localizam as entradas, fichas divisórias, gavetas de catálogo, os "móveis classificadores" ou a mobília contendo conjuntos de gavetas. Os repertórios desenvolvidos não eram, porém, compostos apenas por fichas bibliográficas e pelos textos em si, pois a eles foram acrescentadas ilustrações, quadros esquemáticos e tabelas. Nas palavras de Otlet:

A combinação desses diferentes elementos... permite o estabelecimento de repertórios de fichas similares a um verdadeiro livro. As fichas constituem as folhas do livro; as fichas divisórias, combinadas de várias maneiras, indicam os capítulos, as seções e parágrafos; a encadernação consiste na própria gaveta, a vareta móvel tem funções como a de uma lombada... Os números de classificação nas fichas são na verdade uma paginação de um trabalho cujo sumário é a tabela de Classificação Decimal. É consultado tão facilmente como um livro. É necessário apenas virar as fichas como se estivesse virando as páginas de um livro lendo-o com grande facilidade (OTLET, apud, RAYWARD, 1975, p. 120-121). ${ }^{2}$

O objeto de estudo da bibliologia é o livro, entendido como o "pensamento fixado pela escrita das palavras ou na imagem das coisas, signos visíveis, fixados sobre um suporte material" (OTLET, 1934, p. 10). Um livro ou documento é composto também por elementos como a linguagem, a realidade objetiva ou por reflexões sobre a realidade, mas, por si só, não constituem o documento do ponto de vista da bibliologia. Tais elementos serão analisados por outras ciências, como a lingüística, a psicologia, a sociologia, entre outras. A bibliologia estuda o livro na sua materialidade e complexidade, pois ele - subentendendo-se também o documento apresenta um duplo aspecto:

é uma obra do homem, o resultado do seu trabalho intelectual e (...) se apresenta também como um dos múltiplos objetos criados pela civilização e susceptíveis de atuar sobre ela; isto é próprio de todo objeto que tem caráter corporal e é composto tecnicamente (OTLET, 1934, p. 9).

Além disso, é necessário estudar as articulações entre seu conteúdo e continente, do ponto de vista bibliológico; por essa razão, são necessárias as interfaces da bibliologia com outras ciências, tais como a lógica, a psicologia, a sociologia, a lingüística e as técnicas para analisar um objeto que incorpora questões como a produção e transmissão do conhecimento, bem como os aspectos de ordem tecnológica de sua produção.

\section{A bibliologia, por conseguinte, é uma}

ciência geral que abrange [organiza] o conjunto sistemático dos dados relativos à produção, conservação, circulação, e utilização dos escritos e dos documentos de toda espécie (OTLET, 1934, p. 9).

Ou, com o poder de síntese de Otlet, o objeto da documentação é o "ser documentado assim como o objeto da lógica é o ser racional” (OTLET, 1934, p. 11).

O livro e o documento "trouxeram o ser humano para uma nova realidade: a materialização do pensamento" (OTLET, 1934, p. 425). O estudo do livro implica, nessa medida, o exame de sua forma e substância, com o objetivo de apreender a evolução do pensamento registrado. Em última análise, trata-se de verificar como o conhecimento foi estruturado no decorrer da evolução humana. O estudo do ser documentado requer, desse modo, uma ciência de caráter geral que atue como auxiliar das outras ciências.

A documentação, que tem um objeto de estudo de tal complexidade, deverá

constituir-se num corpo sistemático de conhecimentos como ciência e doutrina por um lado; de outro, em técnica e uma terceira parte em corpo sistemático de organização (OTLET, 1934, p. 11).

No plano da ciência deverá desenvolver estudos teóricos para compreender seu objeto de maneira abrangente. Assim, serão estabelecidas as interfaces com ciências como a lógica e a psicologia, pois é no contexto dessas 
ciências que serão estudados os processos de criação intelectual, por parte do autor, bem como os de assimilação da leitura por parte do leitor; no plano da tecnologia, estuda os meios materiais de produção e multiplicação do livro e do documento; no plano social, dialoga com a sociologia, pois o livro influencia os indivíduos e transforma a sociedade e, como produto da sociedade, traz seus dados culturais. No plano da aplicação técnica "deve utilizar regras que englobem todo o ciclo de vida do documento" (OTLET, 1934, p. 11); e finalmente, no plano da organização faz o estudo das "forças individuais e do trabalho coletivo e de cooperação" (OTLET, 1934, p. 11). Neste último plano, são modeladas as redes cooperativas.

\section{Acerca da metodologia de Otlet}

Com relação aos métodos da documentação, Otlet acredita que eles são os mesmos das outras ciências. A documentação é uma "ciência" tão abstrata e própria para constituir sistemas documentais por meio do raciocínio como as matemáticas. A aplicação da matemática à documentação é feita por meio da estatística e da bibliometria. Um exemplo de estudo bibliométrico, relatado no Traité de Documentation, trata da freqüência de leitura de um autor e demonstra admiravelmente como as técnicas de mensuração do livro podem também contribuir para o entendimento dos acontecimentos no campo social:

De 1740 a 1778 fizeram-se dezenove coletâneas da obra de Voltaire, sem contar as edições separadas, bastante numerosas para seus principais escritos. De 1778 a 1815, Quérard indica seis edições das obras completas, sem contar duas edições incompletas. Por fim, para o período de 1815 a 1835 , em vinte anos, Bengesco encontra vinte e oito edições das obras completas. Nada foi editado de 1835 a 1852 . De 1852 a 1870 , cinco edições, das quais a de propaganda do diário 'Le Siècle'.

(...) No total, [verificou-se] grande consumo [das obras de Voltaire] até a Revolução; depois queda até 1815; prodigioso aumento da demanda sob a Restauração; depois nova queda; foi notado um retorno sensível sob o segundo império. Esta curva tem correspondência com a dos movimentos liberais; imprime-se e reimprime-se Voltaire, sobretudo nas épocas em que estes movimentos encontram mais resistência e se tornam mais violentos. Não obstante, seja necessário levar-se em conta que, sob a Revolução, depois da edição de 1775 e das duas edi- ções de Kehl e sob Luís Felipe, após vinte e oito edições que se sucederam em vinte anos, o mercado estava saturado; o público precisava de tempo para absorver a produção das livrarias (OTLET, 1934, p. 15).

Otlet busca parâmetros metodológicos também nas ciências naturais e os adapta à documentação. Tal como nas ciências naturais, a observação direta é utilizada para a descrição dos fatos, acrescida da cooperação dos pesquisadores, pois os fatos relativos ao livro são tão diversos e possuem tantas peculiaridades quanto as culturas que os produziram, tornando impossível para uma só pessoa observá-los. Está implícito aqui o caráter de cooperação e de internacionalização desses estudos, por não ser possível um só pesquisador estudar em profundidade todos os documentos produzidos em todos os países.

Uma vez reunidos e analisados os fatos, é necessário realizar generalizações para a elaboração de uma teoria. Porém, diferentemente das ciências naturais, o objeto de estudo da documentação é uma criação humana, um produto da vontade humana; a especulação aqui se traduziria na imaginação e na invenção, que desempenham importante papel na construção científica, seja projetando as formas dos livros e documentos no futuro, ou analisando as implicações que elas possam apresentar para a sociedade. Otlet também adapta conceitos da biologia como os de evolução, hereditariedade e seleção. $\mathrm{O}$ conceito de evolução é importante nos estudos bibliológicos porque insere de maneira racional e lógica no seu quadro de estudos, uma criação humana, o livro

que evolui juntamente com a sociedade e os costumes. (...) Herança é encarada como a acumulação de todos os materiais do passado e a seleção, que é uma escolha feita por muitas razões, para continuar transmitindo uns e rejeitando outros (OTLET, 1934, p. 23).

Por fim, Otlet formaliza o método da documentação:

A documentação é uma ciência de observação que, uma vez chegada à expressão de certas relações gerais, serve-se do método dedutivo para generalizar seus dados, e dos métodos de combinação e de invenção para imaginar dados novos. As investigações têm como finalidade determinar as propriedades do livro e do documento e, com estas, sua natureza específica segundo as leis de sua ação. O objeto de investigação é ou o descobrimento das causas ou o das leis e a definição dos tipos (OTLET, 1934, p. 23). 
AFORMULAÇÃODOPRINCÍPIOMONOGRÁFICO

A fundamentação teórica do Princípio Monográfico é conseqüência dos estudos e observações sobre o livro, da concepção de ciência e da sustentação teórico-metodológica que Otlet desenvolveu para forjar a documentação.

Observando seu enunciado sobre o problema fundamental da documentação, exposto a seguir, percebe-se a linha de raciocínio que leva à formulação do Princípio Monográfico, que considera dois aspectos: conteúdo e forma.

A documentação é somente o terceiro termo de uma tríade: Realidade, Conhecimento, Documento. Por conseqüência, a documentação tem como problema fundamental a formulação de métodos próprios, para resgatar do empilhamento de documentos as verdades originais, importantes, não repetidas e colocadas num quadro sistemático das ciências. Este problema tem alguma analogia com a metalurgia, que tem como objeto um método para separar da ganga dos minerais cuja rotulação é mais ou menos elevada (OTLET, 1934, p. 25).

Sob essa perspectiva, interpreta-se a documentação como uma "ciência" que organiza os documentos, encarados como materializações da ação da inteligência humana sobre a realidade. Compete à documentação estabelecer métodos para a seleção e o tratamento dos "dados intelectuais" encaixando-os no "quadro sistemático das ciências" (OTLET, 1934, p.25) para que possam ser acessados. Em outras palavras, à documentação compete tratar o conteúdo dos documentos, a informação. Não se pode deixar de considerar que, possivelmente, a inspiração para a elaboração do Princípio Monográfico se encontre nas estruturas do próprio livro, representadas pelos índices remissivos e notas de rodapé.

No segundo aspecto, o da forma, a documentação aborda as estruturas nas quais os documentos se apresentam, considerando-as como "meios de transmissão de dados informativos para o conhecimento" (OTLET, 1934, p. 25), não importando a distância no tempo e no espaço. Otlet entende o livro/documento também como uma síntese do desenvolvimento tecnológico da sociedade, sendo, portanto, um objeto em evolução. A tecnologia, por sua vez, torna mais fáceis e rápidos os processos de transmissão do conhecimento e, em decorrência, a sua assimilação pela sociedade.

Acredita-se que os aspectos de fundo e forma, ou seja, o tratamento bibliológico do conteúdo dos documentos, bem como as projeções sobre suas formas futuras estejam sintetizadas na elaboração do Princípio Monográfico, uma das soluções encontradas por Otlet para organizar o conhecimento. No Princípio Monográfico subjazem as questões de fundo à medida que seleciona o material a ser incluído no sistema; e de forma, por meio da fragmentação dos textos. Trata-se, em última análise, de evolução, seleção e herança.

Retomando-se o enunciado de Otlet sobre o problema fundamental da documentação, verifica-se a analogia entre os métodos documentários e a metalurgia quando se refere ao "resgate das verdades originais do empilhamento de documentos" (OTLET, 1934, p. 25).

Otlet considera que o livro/documento contém imperfeições, erros, repetições, porque ele "só transcreve uma parte dos dados científicos (imperfeição dos livros)"; além disso, os livros/documentos "transmitem tanto os conhecimentos falsos quanto os verdadeiros (erros dos livros)"; também "transcrevem várias vezes os mesmos conhecimentos (repetições). Otlet refere-se também à dispersão das informações, visto que não se faz "a recompilação dos conhecimentos em poucas obras, mas o dividem e disseminam por inumeráveis volumes (fragmentação e dispersão)" e não se coordenam “os fatos expostos segundo um grau de importância e de utilidade (mesclam o principal e o secundário)" (OTLET, 1934, p. 373). Para superar esses problemas, propõe que seja feita uma mineração de dados para permitir a "extração da massa inumerável dos livros e dos conhecimentos verdadeiros, eliminando os erros e as repetições e ordenando-os de maneira que fiquem dispostos em série e que se separe o principal do assessório" (OTLET, 1934, p. 373). Sua proposta é a de facilitar e agilizar o acesso à informação, por meio da fragmentação do suporte que, reorganizado, proporciona unidade do conteúdo.

Os livros/documentos são produzidos pelo autor que observa e estuda uma dada realidade. Quando elabora o texto, o autor recorre ao seu acervo de conhecimentos que são modelados pela sua visão de mundo. Portanto, os documentos escritos são produtos da interpretação do autor sobre a realidade, tratando-se de uma construção pessoal na qual a subjetividade é inerente. Além disso, algumas repetições podem ser necessárias no texto, tais como revisões de literatura, citações de outros textos e mesmo de exemplos, todas elas úteis para fundamentar ou explicitar a informação original apresentada, mas que não são necessariamente novas.

O Princípio Monográfico trata de extrair as unidades intelectuais ou as "verdades originais" dessa linearidade 
por meio da fragmentação do texto, seleciona-as segundo necessidades contextuais. Essas novas unidades informacionais são constituídas pela unidade intelectual e pelo novo suporte (fichas e folhas soltas). Trata-se de um método para processar a informação que está contida nos livros/documentos. Interfere no aspecto formal do livro/documento, ao retirar as repetições do contexto informativo. $\mathrm{Ou}$, na analogia de Otlet, trata-se de "separar da ganga os minerais cuja rotulação é mais ou menos elevada”. Essa analogia pode ser entendida como uma referência à linearidade do livro/documento que faz com que as novas informações se "misturem" com os demais aspectos que compõem a construção do texto.

O processamento dessa nova unidade informacional é completado por outros dois princípios; o da Continuidade e da Pluralidade da Elaboração, que se imagina tratar-se do acréscimo de anotações que completem o sentido da unidade intelectual estabelecida pelo Princípio Monográfico, tais como a fonte de onde a informação foi retirada, atribuição do número de classificação, remissões e outras anotações relevantes; o terceiro Princípio, o da Multiplicação dos Dados, é a cópia desta unidade informacional para que constituam as entradas do sistema nos diversos aspectos aos quais possa ser relacionado, tais como o cronológico, o geográfico etc.

Pode-se traçar uma analogia entre o processamento da informação realizado por Otlet, nos repertórios produzidos no IIB e os registros dos sistemas de informação computacionais atuais. A unidade informacional dos repertórios é obtida pela aplicação de três princípios, o Princípio Monográfico, o Princípio da Continuidade e da Pluralidade da Elaboração e o Princípio da Multiplicação dos Dados, que, em conjunto, geram registros que contêm informações sobre a fonte de referência, o número de classificação da CDU e demais anotações. A unidade informacional, assim padronizada, pode ser multiplicada para ser inserida nos repertórios, segundo os vários pontos de acesso considerados úteis para recuperar informação. Observa-se, portanto, que esses processos e produtos são semelhantes aos processos de elaboração das atuais bases de dados bibliográficas.

A modificação formal introduzida pelo Princípio Monográfico proporciona uma nova maneira de organizar os saberes, ou seja, um sistema de informação mais flexível que permite realizar a inserção de elementos considerados importantes e a omissão dos elementos que não sejam considerados úteis. Essas operações permitem classificar ou rearranjar as informações conforme a necessidade do usuário. A partir das novas opções de acesso que a estrutura de relacionamentos por assuntos oferece, possibilita economia de tempo e estimula novas formas de leitura mais próximas aos processos mentais do usuário, proporcionando-lhe economia de tempo.

\section{CONSIDERAÇÕES FINAIS}

O Princípio Monográfico é uma das contribuições mais importantes de Paul Otlet para a documentação e posteriormente para a ciência da informação. Para realizá-la, utiliza os conceitos de suporte da informação (documento) e de conteúdo informacional (mensagem), permitindo, dessa maneira, relacionar informações que se encontram dispersas em diferentes documentos, proporcionando a elaboração de novos sentidos. Obtêmse, com esses procedimentos, novos documentos que contêm informação também nova. Existe aqui, portanto, um duplo movimento: desmaterialização e virtualização de documentos e sua transformação em informação nova, fruto da recombinação de informações, que comporão um novo documento.

O Princípio Monográfico representa a solução, reunir a informação que se encontra dispersa em inúmeros suportes. Otlet modifica a forma do documento, fragmentando-os, e reorganiza os conteúdos de forma a gerar novos todos informativos. Os objetos informacionais, elaborados segundo o Princípio Monográfico, assemelham-se aos registros das bases de dados e aos objetos hipertextuais, porque são unidades de informação que podem ser compreendidas isoladamente. Porém, se inseridos em contextos mais amplos, como as bases de dados ou sistemas hipertextuais, podem ser reinterpretados e relacionados de diversas maneiras, dependendo do acervo de conhecimento de cada indivíduo, bem como de seus objetivos.

Percorrer os registros de uma base de dados é, na contemporaneidade, uma função-chave para identificar informação pertinente, assim como a navegação em textos, por meio das âncoras de um hipertexto. Tais conceitos estavam implícitos nos repertórios elaborados no IIB.

O Princípio Monográfico é o conceito no qual os repertórios se baseavam, é o processo de construção da informação que pode ser relacionada pelo indivíduo de acordo com seus processos mentais e capacidades de associação de idéias. Tal maneira de lidar com a informação é inovadora e levava em consideração o pesquisador.

Foram essas as contribuições de Otlet, aqui apenas enunciadas. Novas escavações na obra otletiana e nas obras de seus biógrafos e est-udiosos certamente revelarão outras facetas do trabalho daquele que criou, pela primeira vez, a idéia das redes planetárias de informação. 
Como o presente texto focou o estudo das origens da documentação e da elaboração do Princípio Monográfico, fica para novo trabalho uma investigação mais aprofundada sobre o relacionamento dos princípios de Otlet com a internet.

Artigo submetido em 11/12/2007 e aceito em 03/04/2008.

\section{REFERÊNCIAS}

BLANQUET, M. F. La fonction documentaire: etude dans une perspective historique. Documentaliste, Paris, v. 30, n. 4/ 5, p. 199-204, 1993.

BUCKLAND, M. K. Information as thing. Journal of the American Society of Information Science, New York, v. 42, n. 5, p. 351-360, 1991.

. Information retrieval of more than text. Journal of the American Society for Information Science, New York, v. 42, n. 8, p. 586-588, 1991.

. What is a document? Journal of the American Society of Information Science, New York, NY, v. 48, n. 9, p. 804-809, 1997.

CAMPELlO, B. S.; MAGALHÃES, M. H. A. Introdução ao controle bibliográfico. Brasília, DF: Briquet de Lemos, 1997.

DAY, R. P. Otlet's book and the writing of social space. Journal of the American Society for Information Science, New York, NY, v. 48, n. 4, p. 310-317, 1997.

ESTIVALS, R. La bibliologie. Paris: Presses Universitaires de France, 1987.

FONSECA, E. N. A classificação decimal universal no Brasil. In: BRADFORD, S. C. Documentação. Rio de Janeiro: Fundo de Cultura, [s.d.]. p. 269-278. Apêndice.

$\overline{\text { Cultrix, }} 19 \overline{8} \overline{6}$.

Bibliometria: teoria e prática. São Paulo:

FROHMANN, B. Discourse and documentation: some implications for pedagogy and research. Journal of the Education for Library and Information Science, State College, PA, v. 42, p. 13-28. 2000. Disponível em: <http:// www.fims.uwo.ca/people/faculty/frohmann/Jeles.htm>. Acesso em: 18 abr. 2004.

. Documentation redux: prolegomenon to (another) philosophy of information. Library Trends, Urbana, IL, v. 52, n. 3, p. 387-407, 2004.
GOMES, H. E. O pensamento de Paul Otlet e os princípios do UNISIST. 1975. Tese (Livre-Docência)- Universidade Federal Fluminense, Niterói, 1975.

GUÉRIN, J. L.; MARCHAND, Y. De l'hypertexte à l'expertexte ou du savoir ai savoir-faire. Associations Transnationales, Bruxelles, v. 55, n. 1/2, p. 94-106, 2003.

LEVIE, F. Paul Otlet et le multimédia. Associations Transnationales, Bruxelles, v. 55, n. 1/2, p. 53-59, 2003.

LÓPEZ YEPES, J. Teoria de la documentación. Pamplona: Universidad de Navarra, 1978.

MCGARRY, K. Da documentação à informação: um contexto em evolução. Lisboa: Presença, 1984.

OTLET, P. Traité de documentation: le livre sur le livre: théorie et pratique. Bruxelles: Mundaneum, 1934.

. Documentos e documentação. In: COONGGRESSO DE DOCUMENTAÇÃO UNIVERSAL, 1937, Paris. Discursos... Rio de Janeiro: Imprensa Nacional, 1947. Separata. Disponível em: < http:// www.conexaorio.com/biti/otlet >. Acesso em: 08 jan. 2002.

PEREIRA, M. N. F. Prefácio. In: PEREIRA, M. N. F.; PINHEIRO, L. V. R. (Org.). O sonho de Otlet: aventura em tecnologia da informação e comunicação. Rio de Janeiro: Ibict, 2000.

RAYWARD, W. B. The case of Paul Otlet, pioneer of information science, internationalist, visionary: reflections on biography. Journal of Librarianship and Information Science, London, v. 23, p. 135-145, 1991. Disponível em: <http:// a lexia.lis.uiuc.edu/ $\sim$ wrayward/ot let/ PAUL_OTLET_REFLECTIONS_ON_BIOG.HTM $>$. Acesso em: 31 juĪ. 2004.

. Knowledge organisation and a new world polity: the rise and fall and rise of the ideas of Paul Otlet. Associations Transnationales, Bruxelles, n. 1/2, p. 4-15, 2003.

. The life and work of Paul Otlet: visions and reality. 2002. Disponível em: <http://www.mundaneum.be/ media/expo/otlet.pdf>. Acesso em: 14 jan. 2004.

The origins of information science and the International Institute of Bibliography/ International Federation for Information and Documentation (FID). Journal of the American Society of Information Science, New York, NY, v. 48, n. 4, p. 289-300, 1997.

. The universe of information: the work of Paul Otlet for documentation and international organization. Moscow: VINITI, 1975.

. Visions of Xanadu: Paul Otlet (1868-1944) and hypertext. Journal of the American Society for Information Science, New York, NY, v. 45, n. 4, p. 235-250, 1994.

\footnotetext{
${ }^{1}$ Otlet, P. In: Rayward, W.B. (1990). International organization and dissemination of knowledge: selected essays of Paul Otlet. Amsterdam: Elsevier, p. 84

2 "Section VII, formation des répertoires bibliographiques; subdivision 16: fonctionnement des repertoires à fiches", Manuel abrégé du Répertoire Bibliographique Universel, p.73.
} 